BIBLIOGRAFIA 


\section{Charles Garnier (1825-1898) Um arquiteto para um Império}

Heliana Angotti-Salgueiro'

Resenha de: GIRVEAU, Bruno et al. (Org. e Cur.). Charles Garnier. Un architecte pour un Empire 2 . Catálogo. Textos de Bruno Girveau, Anne-Marie Garcia (curadores da exposição homônima) e de Jean-Michel Leniaud, Marie-Laure Crosnier-Leconte, Olivier Liardet, Maud Domange, Mathias Auclair, Laure de Hody, Juliette Jestaz, Mercedes Volait. Paris: Les éditions de l'École nationale supérieure des Beaux-Arts, 2010, 351 p., ilustr.

Quando Paris assume o papel de capital da fotografia por um mês, em plena estação outonal de lançamentos de livros e aberturas de exposições no gênero (mais de sessenta, sem contar o evento Paris Photo, no Carrousel do Louvre), quando a arquitetura do século XIX parecia esquecida e afastada do circuito cultural, uma exposição sobre Charles Garnier (1 825-1898), acompanhada de um catálogo de 351 páginas, não deixa de surpreender e maravilhar. A começar pela imagem imprevista da capa, cena-evento do cinema hollywoodiano incluída nas projeções da entrada da exposição: vê-se aí, Audrey Hepburn descendo a grande escadaria do Palais Garnier, "instante decisivo" do filme Funny Face [Cinderela em Paris], de Stanley Donen, de 1957, sob o som do prelúdio de Tristão e Isolda, de Wagner lecos de cena de Love in the afternoon, do mesmo ano, em telão paralelo). Surpresas e efeitos gradualmente concebidos, que caracterizam a arquitetura de Charles Garnier, são retomados na montagem, sob trilha sonora de trechos de óperas de seus compositores preferidos, Verdi, Gounod, Delibes e Meyerbeer, trazendo incontida emoção ao visitante.

Cenografia, exposição, catálogo - textos e iconografia de Charles Garnier, un architecte pour un empire associam-se com rara qualidade em vários níveis; porém, não se pode tratar do catálogo sem partir da mostra, que precede sua leitura. $\bigcirc$ canadense Robert Carsen, responsável pela montagem e direção artística da exposição, autor de cenografias recentes de óperas memoráveis no
1. Doutora em História da arte pela EHESS de Paris, atualmente pesquisadora do Núcleo de Pesquisas Brasil-França (Nupebraf), IEA-USP; entre suas publicações individuais e coletivas, destacam-se La Casaque d'Arlequin. Belo Horizonte une capitale ecléctique au $19^{e}$ siècle, Cidades capitais do século XIX, A Comédia Urbana: de Daumier a Araújo Porto-Alegre, O olbo fotográfico: Marcel Gautberot $e$ seu tempo. E-mail: <angotti@usp.br>.

2. Exposição apresentada na École Nationale Supérieure des Beaux-Arts, em Paris, de 26 de outubro de 2010 a 9 de janeiro de 2011. 
3. Trata-se do edifício do Quai Malaquais, da École des Beaux-Arts de Paris - onde Garnier é admitido como aluno em 1842, aos 17 anos -, concebido por um de seus mestres, Félix Duban; este último (com Labrouste, Duc e Vaudoyer), é considerado um dos quatro arquitetos "românticos progressistas" da primeira geração do século XIX.

4. Para entender o sistema e a hierarquia de ensino de arquitetura da École des Beaux-Arts de Paris, ver a obra que marcou época, dirigida por Arthur Drexler, The Architecture of the École des Beaux-Arts, Londres, Secker and Warburg, 1977; para considerações aplicadas e bibliografia complementar, cf. a segunda parte do meu livro La Casaque d'Arlequin. Belo Horizonte, une capitale ecléctique au $19^{e}$ siècle, Paris, Éditions de 1'École des hautes études en sciences sociales, 1997. próprio Palais Garnier, no Scala de Milão, e em outros grandes teatros, soube entender as escolhas dos curadores: "apresentar um retrato íntimo do artista e um panorama de sua obra [...] entre razão e fantasia, à imagem de sua personalidade e do que construiu". Aliás, o parti-pris declarado nos textos dos curadores é o gênero biográfico, por vezes até factual e personalista - l'homme... antes de tudo, mas sem deixar de lado a contextualização das situações vividas, apoiadas em farta documentação, no empenho de ligar, todo o tempo, o que o arquiteto-artista viu, escreveu e realizou.

Ao considerar a adequação do espaço da montagem ${ }^{3}$ ao tema, Carsen distribui muito bem as quase trezentas obras ao longo dos quatro módulos, assim pensados pela curadoria:

I. Viver (o homem, o outro Charles Garnier, sua família, próximos e colaboradores);

II. Estudar, viajar (a Escola de Belas Artes, a ltália, a Europa, o Oriente: o gosto pelos outros lugares e pela policromia);

III. Construir (primeiros passos e encomendas, a nova Ópera, efeitos da Ópera);

\section{Garnier depois de Garnier: o espetáculo continua.}

Segundo a lógica de uma promenade biográfica, que deve "falar aos olhos, aos ouvidos, ao coração e às paixões" (expressão em Le Nouvel Ópera), a montagem é pontuada por citações pertinentes de livros do próprio Charles Garnier ou extraídas da sua correspondência, explicitando as teorias da obra arquitetural que vai torná-lo uma celebridade. A conhecida fotografia do escritório de arquitetura de Garnier, feita por Louis-Émile Durandelle, parece ter servido de modelo à primeira sala da exposição: longas mesas em sequência paralela, exibindo exercícios típicos dos concursos da escola (rendus) de um aluno de primeira classe 4 , projetos, carnês de croquis de viagens, aquarelas, pinturas, fotografias, efígies e caricaturas originais, tudo isso em meio a atributos do métier que funcionam como elementos da cenografia: projetos enrolados, lápis e instrumentos de desenho displicentemente jogados sobre essas mesas-vitrine.

O material exposto, em grande parte inédito, conta passos da vida do mais popular e retratado artista do século XIX, destacando dois momentos-chave de sua formação: o primeiro é o Grand Prix de Rome, em 1848, obtido por Garnier aos 22 anos, e sua consequente permanência na Villa Médicis por cinco anos (importante experiência de formação visual, vivida fora das fronteiras francesas, acumulada nas inúmeras viagens de observação da arquitetura e dos tipos e paisagens da ltália, Grécia e Oriente); o segundo destaca a vitória no concurso do teatro da Ópera, em 1860, frente a 171 concorrentes, e a epopeia de quinze anos de sua construção, destacando a intensa atividade profissional daquele que criou um estilo próprio inscrito no seu tempo llembre-se de que o apogeu de Charles Garnier é sob Napoleão III, no Segundo Império francês).

$\mathrm{Na}$ grande sala-galeria do segundo andar, organizada conforme a planta do teatro da Ópera e revestida de painéis laterais que recriam uma 
espacialização em 3D, estão expostos os belos desenhos aquarelados das elevações do Nouvel Opera, plantas, vistas, ângulos e detalhes ornamentais, esculturas, pinturas, e fotografias da notável campanha documental de Durandelle, além do projeto do rival Viollet-le-Duc, terminando com as demais realizações de Garnier, depois da Ópera. Uma vez vista a exposição e lido o catálogo, evidencia-se a harmonia do trabalho partilhado entre os responsáveis pela mostra e os autores dos textos, sobre os quais passo a comentar.

Nove ensaios preliminares (páginas 14 a 139), entre eles dois assinados pelos curadores e os demais por outros estudiosos do século XIX, esclarecem com minúcias temas que precedem o catálogo propriamente dito. Permeados de rica iconografia, esses ensaios tratam dos seguintes temas: "Uma arquitetura 'que fala aos olhos, ouvidos, ao coração e às paixões'" (Bruno Girveau, curador); "Charles Garnier, um oponente à centralização estilística da encomenda pública" e "Caracterizar a obra de Garnier" (Jean-Michel Leniaud); "Charles Garnier, viajante iluminado ou sonhador impenitente?" (Olivier Liardet); "Charles Garnier e sua rede de relações" (Maud Domange); "Charles Garnier e a fotografia" (Anne-Marie Garcia, curadora); "Um concurso para a Ópera" e "O escritório [l'agence] de Charles Garnier para a Ópera" (Marie-Laure Crosnier-Leconte); "Charles Garnier e a Biblioteca-museu da Opera" (Mathias Auclair).

Segue-se o bloco do catálogo (páginas 140 a 301), com textos mais pontuais, que explicam os três principais módulos - "Viver", "Viajar/estudar", "Construir" e seus subitens - acompanhados da relevante iconografia correspondente, segundo sua sequência na exposição /completando as demais imagens mostradas nos ensaios preliminares), cuja numeração sequencial elimina a autonomia da "lista de obras" de praxe. O quarto módulo - "Garnier depois de Garnier: o espetáculo continua" - é assinado pelo curador Bruno Girveau, que, ao tratar, (em texto por demais sucinto) da "popularidade" do arquiteto-celebrity, traz observações sobre as referências feitas pelo cinema ao teatro da Ópera, deixando de lado as apropriações das obras daquele que foi o mais discutido arquiteto do século XIX (voltarei a essa questão no final da resenha).

Ao término do volume, nos anexos, lemos detalhada "cronologia biográfica", pequenas notas de "biografias" de contemporâneos, a listagem classificada por tema dos "livros de Charles Garnier na EBA", e o estado e local da documentação sobre sua obra em "fontes: doações e coleções de Garnier EBA e biblioteca-museu do teatro da Ópera", além de "índice" de nomes e "créditos fotográficos".

Na maioria dos ensaios preliminares, insiste-se no epíteto de artista "romântico", mas alguns autores divergem diplomaticamente na caracterização do estilo de Garnier - se ele era neoclássico ou, sobretudo, neobarroco. Na busca dessa identificação e no julgamento de "valores" do arquiteto, há posições discutíveis e inúteis. Leniaud, que em 2003 já publicou uma biografia de Garnier (deixando a desejar, sob vários pontos), não desenvolve argumentos convincentes ao invocar rapidamente uma referência imprópria e anacrônica, como H. Wölfflin.

Annals of Museu Paulista. v. 18. n.2. July.-Dec. 2010. 
Busca etiquetar Garnier como "barroco", com "tendências" de aticismo e especialmente de asianismo, termos que, no Império Romano distinguiam respectivamente, a "elegância e a sobriedade" e "a sobrecarga decorativa, a cor, a riqueza", e.... pasme-se "um certo tipo de mau gosto"! Julgamento que, recolocado em seu contexto, não quer dizer nada, além da postura formalista superada - basta pensar na historiografia norte-americana sobre o estilo Beaux-Arts e sobre tantos outros aspectos da arquitetura do século XIX, bem como na linha francesa de uma outra história deste século que se seguiu à inauguração do Museu d'Orsay, em 1986. Alusões preconceituosas já foram suficientemente discutidas à luz de documentação que não se lia antes (textos como os do próprio Garnier e de periódicos que the foram contemporâneos), verdadeiras tribunas críticas em que o debate arquitetônico e arquitetural se elevou a níveis invejáveis na história da arquitetura, como a RGA, de César Daly, La Construction Moderne, referências entre tantas outras que, nós, estudiosos do século XIX, nos debruçamos nos arquivos parisienses, e tivemos ocasião de discutir em seminários e colóquios, naqueles anos de revisão.

Na caracterização da obra de Garnier, o curador Bruno Girveau se exprime melhor do que Leniaud, pois prioriza a "fusão bem resolvida das três artes - arquitetura, pintura, escultura e o primado do efeito visual", além do bem lembrado respeito do arquiteto pela clareza do "programa", classificando a Ópera como um dos edifícios mais lógicos e racionais do seu tempo, em que cada função das partes do edifício se expressa externamente na composição dos volumes ao longo de um eixo, da mesma forma que o percurso e as surpresas visuais e decorativas estão perfeitamente bem resolvidos, sustentam-se e se completam. A atribuição do conhecimento da ciência da planta, da arte da composição unificada ou da disposição articulada das partes, enfim da resposta satisfatória à função, é opinião praticamente unânime entre os autores dos ensaios.

Merecem destaque fatos menos conhecidos, como as viagens de pesquisa de Garnier para estudar salas de espetáculos importantes construídas na Europa, especialmente italianas e alemãs, suas cuidadas escolhas técnicas e decorativas - quanto à aeração, acústica, instalação de equipamentos modernos, procura de mármores, execução dos mosaicos, integração de novos materiais -, tópicos tratados em detalhes, que explicam a importância duplamente racionalista e plástica da obra de Garnier no seu tempo.

Mas, sobre o "estilo Garnier" - que ele mesmo qualificou de "Napoleão III" em irônica resposta à Imperatriz Eugénie -, os melhores textos são de Marie-Laure Crosnier-Leconte, para quem o arquiteto não deve ser etiquetado ou visto através de traços desse ou daquele estilo de que se apropria, mas, sobretudo pela maneira como faz a apropriação, como recompõe as referências e, sobretudo, por particularidades que o distinguem e o elevam acima de seus compatriotas e mesmo inimigos (Viollet-le-Duc, o maior deles), ou seja, pela excepcional cenografia e funcionalidade de sua arquitetura. Destaque-se ainda a análise detalhada que Crosnier-Leconte faz de questões menos conhecidas, como das vicissitudes de toda ordem no canteiro de obras vencidas pelo arquiteto e 
competentes colaboradores (uma plêiade de Prix de Rome) de sua agence (cuja importância, quando ainda não existiam escritórios privados de arquitetura, mereceu um texto específico), as dificuldades enfrentadas em relação ao terreno, e especialmente o ajuste do edifício ao espaço urbano, que, em pleno andamento das obras, exigiu modificações que alteraram a escala da fachada. Recolocado no seu tempo e contexto, Garnier é para ela um inovador e um eclético - sem medo do termo, e para os que compreendem o ecletismo la referência é Jean-Pierre Épron) - ele é seu melhor representante, dada sua "arte de escolher entre estilos diferentes, criar uma assemblage jogando com escalas diversas" e integrar os avanços tecnológicos da época: Garnier encarnou como poucos a célebre aliança da história com a arte e a técnica, subentendida no sistema de ensino da escola de Beaux-Arts e lema de Daly em sua revista.

Entre os dados biográficos enfatizados nos ensaios, lê-se que só a partir do concurso para a construção da Ópera, nos anos 1860, a ascensão social e a celebridade profissional marcariam a obra desse modesto filho de um ferreiro e de uma rendeira; e que em 1854, ao voltar de Roma e das viagens de formação, vegetara sem trabalho no seu país e caíra em depressão. Em 1858, graças ao casamento com uma mulher culta lque zelará por seu equilíbrio e por sua posteridade documental, guardando e catalogando seus arquivos), Garnier pode frequentar os meios universitários e letrados da capital francesa, e ao vencer - concurso daquela que se tornaria a mais importante obra do seu tempo, personifica a "meritocracia" artística burguesa típica do século XIX.

O conjunto iconográfico reunido e analisado no catálogo é, como observei, primoroso e cobre outros pontos fundamentais da vida de Garnier, entre eles as centenas de viagens - sua "terapia" e fonte de estudo -, além das fotografias do teatro da Ópera e a produção pós-Ópera. Desse conjunto merecem destaque:

- as aquarelas e croquis das viagens, que formam um corpus impressionante, "reserva de imagens e impressões que the servirão durante toda sua vida de artista" e comprovam o "dom da observação" e seu "entusiasmo excessivo" pela ltália, a Grécia e o Oriente: desenhos de monumentos e seus detalhes ("restaurações" de edifícios da antiguidade), de fragmentos e repertório decorativo, que ressaltam, especialmente, a policromia nos vestígios e nos costumes tradicionais e pitorescos de homens e mulheres, além de paisagens naturais e urbanas.

- as fotografias conservadas em seu acervo, relativas aos lugares que visitou, como a Grécia (fotos de Félix Bonfils) e oriundas das campanhas fotográficas de suas obras, especialmente as de Lovis-Émile Durandelle sobre a construção do teatro da Ópera. Anne-Marie-Garcia, da equipe de curadores da exposição, comenta, porém, a relação de "desinteresse" de Garnier pela fotografia (normal para um adepto do desenho sur le viff, embora ele tenha adquirido séries significativas de souvenirs de monumentos antigos quando frequentava o Caffè Greco, em Roma. Para Garnier, homem de seu tempo, a fotografia 
5. Registro também a exposição concomitante - "L'œil et la plume: caricatures de Charles Garnier", sobre suas caricaturas inéditas, consideradas de valor sentimental, anedótico e burlesco; a maior parte foi feita quando Garnier estava na Villa Médicis, a partir de 1848 , constituindo uma espécie de galeria de retratos satirizando pensionistas amigos como Paul Baudry e Alexandre Cabanel. Mais tarde, ele retrata políticos e empresários de seu tempo, como Haussmann; e entre os portraits -charge de velhos colegas e de personalidades que dormiam nas sessões da Academie des Sciences et Inscriptions et Belles Lettres de l'Institut de France, está D. Pedro II "não passava de uma inovação útil", classificada entre as "artes mecânicas", com fins de exatidão documental e para uso editorial, difusão e circulação de seus projetos. Os clichês da campanha da agência de Durandelle le, com menos importância, os de outros fotógrafos da época, como Charles Marville) testemunham a memória viva do edifício tomando forma na cidade, e conservam a lembrança das fases do canteiro de obras e da execução dos ornamentos /além de terem servido de base para recueils de detalhes e modelos construtivos e decorativos que correram o mundo, como o de Raguenet). Garnier foi fotografado por Nadar e Adam Salomon, porém, na exposição, foram mostrados, sobretudo, inúmeros retratos pintados e caricaturas 5 .

último item da terceira parte do catálogo trata do "efeito" ou das consequências da Ópera - o efeito fica restrito à França, e discorre-se sobre as obras executadas em seguida ao teatro:

- a casa de veraneio da família, ou a villa Garnier (construída entre 1872-1873), em Bordighera, estação balneária na Riviera italiana, onde Garnier se retira esgotado após a inauguração da Ópera em 1875. Lá recebia suas relações artísticas, sociais, de negócios e personalidades; entre elas cita-se o "Imperador do Brasil, don Pedro de Alcântara (1825-1891) deposto em 1889, homem de letras, poeta e sábio, membro da Société géographique, como o filho de Garnier, Christian Garnier. Garnier o encontrava também em reuniões da Academia" (cf. p. 85 e no anexo Biographies, p. 309);

- o cassino de Monte-Carlo (1878-1879), considerado por François Loyer "como a mais bela obra" de Garnier, para a qual ele convoca a equipe de pintores e escultores e alguns arquitetos que já haviam trabalhado na Ópera. Em Monte-Carlo se observa que ele pode lançar mão de um sítio privilegiado para desenvolver seu projeto, sem os limites das avenidas e imóveis haussmanianos de Paris;

- outras obras em Bordighera, no Mediterrâneo, como a villa de Raphaël Bischoffsheim, banqueiro e administrador da companhia de estrada de ferro do Midi, que será o mecenas do observatório astronômico de Nice (projeto de 1879, construído entre 1881-1887, que Garnier fora obrigado a simplificar dado o alto custo), programa inusitado cuja cúpula foi feita com a parceria técnica de Gustave Eiffel, de quem Garnier detestará a torre de 1889; entre as obras fora da capital, destacam-se ainda o cassino e partes do complexo termal de Vittel (1883-1885), e um raro exemplar de arquitetura religiosa (terminado em 1886) em estilo "vagamente Lombardo", em Aisne, na Picardie. 
Naqueles anos, além de dedicar-se à redação do seu livro sobre a Ópera, "o arquiteto imperial" passa a ser convocado para responder à pompa da Terceira República. Projeta monumentos e capelas funerárias para músicos e escritores franceses famosos (Bizet, Offenbach e, especialmente, o catafalco para a cerimônia do enterro de Victor Hugo), atendendo a encomendas nesse gênero também na Itália. Constrói algumas obras privadas que marcam ainda o espaço urbano parisiense: o edifício do Cercle de la Librairie (uma associação de profissionais do livro) de 1879, no 117 boulevard Saint-Germain, e o imóvel da família e empresa Hachette, no mesmo boulevard.

A última obra de Garnier são os quarenta e quatro pavilhões da pré-história e história da habitação humana "de todas as épocas e continentes", para a Exposição Universal de 1889, uma espécie de "teoria arquitetural, social e antropológica" do habitat, muito apreciada pelo público, objeto de croquis, aquarelas e do livro Histoire de l'habitation humaine, escrito com a colaboração de Auguste Ammam, que sairá em 1892. (Não confundir com o de Viollet-le-Duc Histoire de l'habitation humaine, depuis les temps préhistoriques jusqu'à nos jours, de 1875.1

Para finalizar o catálogo, um texto de Bruno Girveau ostenta o título "Garnier aprés Garnier: le spectacle continue", do qual se espera conclusão mais detalhada sobre o impacto da obra do arquiteto-people; porém, em apenas duas páginas, o curador não desenvolve a citada "intemporalidade" da sua arquitetura, a fortuna crítica internacional que alimentou sua celebridade, as apropriações na França (e fora dela) que fizeram de seu teatro um ícone. Quando, em 1867, a fachada da Ópera foi desvendada para a Exposição universal, inicia-se a consagração do arquiteto; e o edifício, finalmente terminado e inaugurado em 1875, torna-se não só um marco na "Paris capital do século XIX", mas um modelo internacional para o programa de teatro - uma das poucas obras que a posteridade tornará conhecida pelo nome daquele que a projetou e construiu: Palais Garnier ou Opéra Garnier. Comentários positivos e negativos constituem parte da legenda do edifício, cuja representação polêmica só foi igualada pela Torre Eiffel, vinte anos depois. $\bigcirc$ curador cita, en passant, apenas seus efeitos na literatura e no cinema - o romance $\bigcirc$ fantasma da Ópera, de Gaston Leroux, em 1910, e filme homônimo, em 1925, com décors de superprodução da Universal Pictures, que retomaram a "riqueza insolente" do modelo arquitetural. Comenta que Hollywood eternizará espaços do "teatro cartão-postal" com mais dois filmes, estrelados por Audrey Hepburn: Love in the Afternoon e Funny Face, cujas cenas fecham a exposição. Parece-nos, porém, que a bela imagem usada na capa do catálogo (que citei no início) não passou de uma audácia dos curadores ou de estratégia de marketing editorial, sem maiores conseqüências (Figura 1). Para reforçar sua escolha, Girveau afirma, ainda, que "como o pintor Jean-Léon Gérôme (atualmente exposto um pouco mais adiante, no Museu d'Orsay), Garnier pensou sua arte de forma pré-cinematográfica, nos seus pontos de vista e efeitos".

Alguns poderiam lamentar as poucas referências, ao longo dos textos, ao contexto político urbano na ocasião do projeto maior de Garnier, realizado sob o barão Haussmann, prefeito de Paris; porém este já foi bem estudado e, nos 


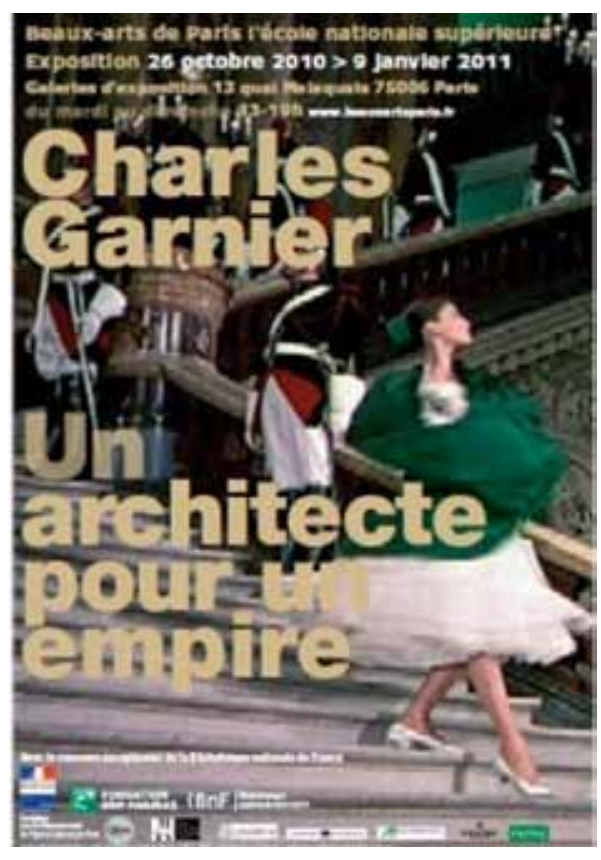

Figura 1 - Audrey Hepburn descendo a grande escadaria da Ópera Garnier, no filme Funny Face [Cinderela em Paris], 1957, de Stanley Donen. Capa do catálogo Charles Garnier. Un architecte pour un Empire. Paris: ENSBA, 2010. () Courtesy of Paramount Pictures Entertainment.

últimos vinte anos, a historiografia sobre o século XIX também permitiu, inclusive, a revisão de posturas ideológicas, conferindo-lhe o devido lugar. De toda maneira, tal ausência não seria coerente à aversão de Garnier pela política e os políticos?

A destacar, enfim, desta obra profundamente densa, descritiva e bem ilustrada, as notas de rodapé - rico aparato documental que permite reconstituir ampla bibliografia sobre a cultura visual da segunda metade do XIX, incluindo os textos contemporâneos às obras arquiteturais e os livros de Charles Garnier, que mereciam ser mais conhecidos: À Travers les arts, causeries et mélanges (1869, reeditado em 1985); Le Théâtre (1871); Le Nouvel Opéra (publicado entre 1878 e 1881 em dois volumes primorosos de pranchas grand folio, sendo o texto do primeiro reeditado em 2001 l; L'Habitation Humaine (com A. Ammann, 1892); sem contar as operetas, vaudevilles, canções, tragédias, saynètes, poemas e contos, de sua autoria, considerados de importância menor frente à qualidade dos livros.

$\bigcirc$ leitor poderá complementar seu conhecimento adquirido em Charles Garnier, un architecte pour un Empire com a leitura de outras publicações sobre o arquiteto e sua obra:

- François Loyer, Les ambigüités de Charles Garnier, prefácio à reedição de Charles Garnier, À Travers les arts, causeries et mélanges. Paris: Picard, 1985. 
- Christopher C. Mead, Charles Garnier's Paris Opera: Architectural Empathy and the Renaissance of French Classicism. Cambridge: The MIT Press, 1991.

- Jean-Michel Leniaud, Charles Garnier. Com a colaboração de Béatrice Bouvier (documentação e catálogo) e Thierry Béghin (fotos). Paris: Monum; Patrimoine, 2003

Resenha apresentada em 11/2010. Aprovado em 12/2010. 